\title{
Role of CRM Initiatives of Life Insurance Corporation of India to Satisfy the Customers
}

\author{
Sucheta Rani ${ }^{1}$ and Anil Kumar Soni ${ }^{2}$ \\ ${ }^{1}$ Research Scholar, IKG Punjab Technical University, Jalandhar, Punjab, India \\ ${ }^{2}$ Associate Professor, DAVIET, Jalandhar, Punjab, India
}

\begin{abstract}
India has a large population base. But the untapped market potential of this population creates a very big opportunity for the life insurance industry. Earlier LIC was having monopoly over life insurance in India, so customers had no choice but after liberalisation, with the entry of private players, customers became aware and they started to compare the product of LIC and the private players. This has created a big challenge for the LIC.As private players are providing innovative products to the customers, so they are capturing the market share of LIC. To overcome this problem, LIC has to do something more than the usual things so that their customers feel reluctant to leave the LIC. So, LIC has introduced the concept of CRM in insurance business. The purpose of this paper is to know in detail the CRM initiatives of LIC, which are helpful to delight the customer. Main findings of the paper are that although LIC has initiated a number of in itiatives to satisfy the customers, yet there is a need to build strong database.
\end{abstract}

Keywords: CRM, ECS, TCF.

\section{Introduction}

Peter F. Drucker, the great management guru defined the modern concept of business as, "to create customers". This definition has changed the concept of business. Although it seems short but has great implications. Here customer is not only a party to contract but a person whose loyalty towards the organisation has to be ensured. Peter F. Drucker has also quoted that "there are only two functions which generate revenue", these are marketing and innovations.[1] There is a need to combine these two definitions; every business should use innovative marketing strategy that is customer centric approach. This strategy and process of acquiring, retaining and developing the close profitable relationship are called customer relationship management (CRM).
CRM is a system for managing company's interactions with current and future customers. CRM is intended for building long term relationship. Some theorists have been considering it as an exercise for customer retention. This requires a variety of techniques, especially post sale initiatives, to keep the customers for life [2\}. So, organisations use techniques to keep their customers satisfied. Relationship marketing is emerging as the core activity for business operating in fiercely competitive environment. On average, businesses spend six times more to acquire customers than to keep them [3].There is a need to pay more attention to provide best services to the existing customers. CRM is an imperative measure in any service sector especially in Indian competitive market. Liberalisation of various sectors has increased the competition manifold. The same thing happened with the LIC i.e. the deregulation of insurance industry created a number of problems for the LIC, the biggest pillar of insurance. After liberalisation, the market share of LIC has been considerably reduced. Private players are paying more attention to attract customers by providing them innovative services. To maintain its position in market LIC felt the need to provide better services than their competitors, that's why the concept of CRM was introduced in LIC.

This paper will focus on CRM applications of LIC related to their communication channels for customers, customer satisfaction and customer retention. At present CRM is the latest idea of managing and propagating insurance business more successfully. It is a tool that helps to design insurance products which match with customer expectations. It also helps to build customer trust and develops loyalty of the customers. The primary objective of an insurance organisation is to maintain clarity in transaction and provide full protection to policyholders. 


\section{Review of Literature}

Pathak and Singh (2003) examined the effect of entry of private players into the insurance sector. A study was conducted of the various marketing strategies adopted by LIC, its strengths and weaknesses. It was concluded that although the insurance companies were spending a lot of money on advertisement but not enough money was being allocated for research and development of new products. [4]

Jagendra Kumar (2008) in his articles on "product doesn't matter service does" states that the CRM technology can help to improve customer service and customer contact [5].

Narayan. H. Jai (2009) has made an emphasis on importance of customer in the business of insurance. He explained in phase of growing market competition, there is an intense need to go beyond mere efficiency in designing products. To understand the customer's needs and fair treatment to them is the need to win their loyalty and trust.[6]

Satish S.V. (2009) contends that insurance marketing requires creativeness of the insurers imply ing updating knowledge on the markets with global perspective which calls for availability of enough right data and information at the operating offices. [7]

Keerthi P and Vijayalakshmi, R (2009) has revealed in his study on the expectations and perceptions of the services in private life insurance companies that private companies are successful in meeting the customers' expectations in terms of some service quality factors. But in case of other variables there is a need to focus on the effective delivery of services only then they can capture the market share [8]

Dr.Arnika Srivastava, Dr. Sarika Tripathi (2012) have analysed that where almost all the industries in the world trying hard for survival due to the major economic meltdown, Indian life insurance industry was one of the sectors that was still observing good growth. [9]

\section{Objectives of the study}

The main objective of the study is to know the innovative CRM practices adopted by LIC.

\section{Sources of Data Collection}

Main source of data collection is secondary. The secondary data is collected from different journals, articles and life insurance company websites. Research methodology is descriptive.

\section{Results and Discussions of CRM Strategies}

LIC is trying its best to provide best services to the customers to retain the exiting customers and gain the new customers, for this LIC has taken some initiatives to satisfy the customers. Some of those initiatives are discussed as under:

\subsection{Policy Guide line and help line}

This section guides the policyholders through the various intricacies of a life insurance contract and the facts that the policyholder must know to make the best out of life insurance policy.

\subsection{Duplicate Policy}

LIC policy bond is the main evidence for policy taken by the policy holder from LIC of India, so it is the most important document from LIC point of view. If the policy is lost due to any reason and it is not traceable, no need to worry, he/she can get a new one (Duplicate Policy Bond) from LIC of India by following the below mentioned procedure and deposit the same in the home LIC branch.

- Form number 3762 is required to be typed at a judicial stamp paper and get it attested from the notary.

- One more form is required and that should be signed by the policyholder.

- Two other documents are required that is One photo id and one address proof along with.

Policyholder is required to pay the stamp charges. The stamp charges differ from plan to plan .Once these documents are ready, then new policy bond will be is sued within two day time.

5.3 Official app from Life Insurance Corporation of India

LIC uses the latest technology like e-mail and mobiles and also using of mobile Apps ultimately resulted in faster and safer customer services in the CRM process. Mobile app is helpful to provide all type of information like product information, premiu $\mathrm{m}$ calcu lator, LIC office locator etc. in their hands.

\subsection{No mination and Alterations}

There may be cases where the policyholder would like to make alterations in the policy like change of premium payment mode, reduction in premium paying term etc. LIC provides for change of addresses, updating of telephone numbers, mobile 
numbers and e-mail addresses in policyholder's contact address information.

The policyholder may change the nomination any time during the lifetime of the policy. Policyholder can even nominate minors, earlier the customer feels reluctant to do all these alterations but now the whole information about the nomination and alterations is online, so everything is at his fingertips.

\subsection{Assignment of policy}

Policyholder will have to assign the policy to LIC or the financial institution in case of raising a loan against the policy, and the policy will be reassigned to the policyholders in case of repayment of the loan. Policy of a policyholder is really helpful to raise the loan.

\subsection{Premium Reminders}

LIC usually sends premium notices one month in advance to the due date of the premiu $m$ by various ways through SMS, e mail, through telephone reminder, alerts etc.

\subsection{Policy Status}

Status of the policy indicates if the policy is in force or has lapsed due to non-payment of premium. The information about the status is available at the branch that services the policies. It is also available through LIC interactive voice response in selected cities. But now the status of policies being serviced in the cities connected by network are also available through network. In selected cities, online touch screen kiosks are also provided where the policyholder can view the policy status.

\subsection{Revival of lapsed policy}

In any case, if the policy is lapsed due to nonpayment of premiums within the due dates or the grace period, then the policy has to be revived but before the expiry of 5 years and before the maturity of the policy. For revival of policy, accumulated premiums with interest has to be paid. There are various different types of revival:

- Ordinary revival: All he/she need to do is just pay all the unpaid premiums along with the interest togetherin some cases, declaration of good health is required along with medical reports.

- Special revival: If a person wants to revive his/her policy under the special revival scheme, then there are few conditions that need to be complete. Such conditions are:
ISSN 2455-6378

- Policyholder has to use special revival scheme for the entire tenure of the policy.

- This scheme can be availed in the initial 3 years of the commencement date.

Instalment Revival: There are many schemes for the ease of customer and instalment revival is one of them. In case where the policyholder is not able to pay the due premium in a lump-sum, then under the revival scheme he can use the instalment option.

- Survival Benefits Cum-Revival Scheme: A policyholder can easily use this scheme to revive the money back policies. A policyholder is required to pay the additional charges in case the amount of revival benefit is more than the survival benefits.

- Loan cum Revival Scheme: A policyholder can also go for loan cum revival scheme. Under the scheme the policyholder can avail this benefit by taking the loan on the date of revival of the policy if it is having the surrender value. He is supposed to pay the extra amount in case of any shortage in the amount of revival and vice versa [9].

5.9 Information about maturity, survival benefits, disability and death claims

LIC sends information to the policyholders in advance when such benefits are due. However, if the amount of survival benefits is less than Rs. $60,000 /-$, then it is sent to the policyholders directly. Till2012, policyholders were required to visit the home branch along with some documents, but now they can take the benefit from anywhere to take these benefits a policyholder is required to submit the following documents.

- Original policy bond of the policy.

- To transfer the maturity value in the account, it is required to submit the duly filled NEFT form along with the cancelled cheque.

- Revenue stamp of Rs1/-. The policy holder needed to sign across the revenue stamp of Rs 1/- pasted on the form.

5.10 Facility of paying the premium through different modes:

- Through ATM: It is available with the Axis bank and Corporation bank.ATM facility for payment of premium has been introduced in December, 2003 with as 
Service provider. This facility is provided at no cost to avail this facility customers are to register themselves through thebank website. Bank sends the registration data for all the policies newly registered on next working day to PCMC required format. If premium is already paid through any other mode before receipt of the payment through ATM or in case of any mis match of premiu m the a mount received through ATM is refunded, it is directly credited to the bank account within 15 days.

- Portal Payment: Online Payment of premium is the biggest initiative of LIC.This facility is available to registered customers only.

- At Cash Counter:

- Premium can be paid at the cash counter of any LIC Branch Office.

- Premium can be paid by CASH/CHEQUE/DD.

- Premium for ULIP policies can now be paid at any LIC Branch cash counter across the country.

- Through ECS: Facility for payment of premium through LIC has been started since March 2004. In this facility bank act as a mediator between the LIC and the policyholder. Bank deducts the amount of premiu $m$ at pre decided dates and later on transferred to LIC. To avail of ECS facility, customer is required to submit mandate form to LIC and also authorizes bank to deduct premium. ECS of RBI is reliable service for payments. This facility is free of cost. The policyholders having accounts in the banks in the cites, which are me mbers of clearing house can avail of this facility for all policies irrespective of the LIC branch to which these policies are attached for servicing.

\subsection{Claims Review Committees}

The life Insurance Corporation settles a number of Death Claims every year. Generally all types of claims are paid except in case of fraudulent suppression of material information. The nu mber of such repudiated cases is, however, very small. Even in these cases, an opportunity is given to the claimant to make a representation for consideration by the Review Committees of the Zonal office and the Central Office. After the hearing, appropriate decisions are taken. [12] This facility will really help to build the confidence of policyholders that will definitely lead to more satisfaction.

\subsection{Satellite Offices}

LIC has opened the satellite offices in the country. Due to this branch network is linked up with the Head Office. It will help to provide improved services to the customer.

\subsection{Treating the customer fairly}

TCFis an innovative step of LIC that has given equal importance to every customer. It will help to build the confidence of the customer.

\subsection{Customisation of life insurance products}

It has enabled customers to choose among variety of life insurance products that are need based and customer centric.Insurance Selector helps the policyholder in deciding which plan is suitable according to the age, occupation, income and insurance needs.

\subsection{Online premium calculator}

Online premium calculator generates an instant illustration for premium. All these things will definitely help the customers to decide the best products.

5.16 Grace period facility for payment of premiu m

Although it is duty of the policyholder to pay the premium on the due dates, but still grace period of 15 days for monthly premiums and not less than one month grace period is allowed for quarterly, half-yearly and yearly premiu ms.

\subsection{Installation of informationkiosks}

LIC has set up 150 interactive touch screen based multimedia kiosks in metro and some other cities for dissemination of information to the public for the products and services of LIC. These points are helpful to provide policy details.

\subsection{Grievance Redressal Machinery [12]}

In a vast organization like LIC, catering to the various needs and aspirations of millions of policyholders, grievances of customers do arise occasionally. In order to redress these grievances LIC has designated Grievance Redressal Officers at all levels of the Organization:

- At the Branch level: The Sr. /Branch Manager

- At the Divisional level: Manager, CRM

- At the Zonal level: THE regional manager CRM

- At the Central level: The Executive Director CRM/Chief (CRM) 
For the redressal of any grievance Policyholders can meet personally these designated Officials. The redressal Officers are available at their Offices for personal interviews with the customers on every Mondays except on holidays without prior appointment. Customers can meet the Grievance Redressal Officers on other days also with prior appointment. The names of the Grievance Redressal Officers are displayed in the respective Offices and are periodically published in the local newspapers.

\section{Conclusions}

CRM practices of LIC have seen a drastic change over the past few years.to achieve successful CRM, a company should understand what is and why it is beneficial to customers in order to retain them for long time. Customers give priority only to satisfy their needs. The success rate of CRM depends upon the quality of CRM. From the paper it is concluded that although LIC has taken a large number of initiatives to satisfy their customers, yet there is a need to build a strong database of customers. It is possible only if the LIC will conduct regular surveys and interact with the customers. Moreover most of CRM services are at fingertips, sometimes, some customers are not comfortable with technology. Some assistant should be provided to assist them.LIC should introduce new ways that makes the customers more delightful and help to attract new customers

\section{References}

[1] Jadhav N.R. "A Study of Customer Relationship Management (CRM) Practices in the Insurance Sector in Maharashtra State", International Journal of Science and Research Methodology, Vol. 8, Is sue 4, February (2018).

[2] Dr.Shanmugasundaram A, Srilekha K S, Customer Relationship Management" IOSR Journal of Business and Management(IOSR_JBM), Vol 19, issue 6, Version 2 (June 2017) pp 31-35.
[3] Bhaskara Udaya B and Rao Syamala G. "Innovative CRM practices in the Indian Life Insurance Industry", Journal of Advance Management Research, ISSN 2393-96, Vol. 5, Is sue 5, (2017).

[4] Pathak, P. and Singh, S. "Increasing Competitiveness through Marketing - A Case Study of Life Insurance Corporation of India", The Alternative Journal of Management Studies and Research, Vol. 2, No. 1, Page No 32-38, (2003).

[5]Ku mar Jagendra "Product doesn't matter service does", the journal of insurance institute of India, January-June (2008).

[6] Narayana. J. "Role of CRM in life insurance business", IRDA journal, Vol. 1, No. 3, Issue 15, April (2009).

[7] Satish S. V."Life insurance marketing - A phenomenon", southern economist, February 15,(2009)

[8] Keerthi, P.A and Vijayalaxami, R. "A Comparative Study on the Perception level of the Services Offered by LIC and ICICI Prudential" Indian Journal of Marketing, August (2009).

[9] Srivastava Arnika and Tripathi Sarika, "Indian Life Insurance Industry - The Changing Trends", International Refereed Research Journal Vol. - III.

[10] Economic Times article on "how to revive lapsed life insurance policy" February 122018.

[11] Krishnamurthy $\mathrm{K}$ and Karthikayan K "Customer Relationship Management Practices in Life Insurance Companies in Chennai city", International Journal of World Research, Vol. I, Is sue 32, August (2016).

[12] Page "Grievance Redressal System in LIC of India" Retrieved from https://www.licindia.in/ Bottom-Lin ks/grievance-redresal-system, "n.d.", date assessed: 05-05-2019. 